\title{
USING ASYNCHRONOUS LEARNING IN REDESIGN: REACHING AND RETAINING THE AT-RISK STUDENT
}

\author{
Carol A. Twigg \\ Executive Director \\ Rensselaer Polytechnic Institute
}

\section{INTRODUCTION}

Many students who begin postsecondary education drop out before completing a degree. According to the Lumina Foundation, an estimated 60 percent of students at public institutions fail to complete degrees within five years, and half of these students leave during the freshman year. As shown by research by the Policy Center on the First Year of College at Brevard College (NC) and others, the first year of college is the most critical to a college student's success and to degree completion.

Successful completion of introductory courses is critical for first-year students, but typical failure rates in these courses contribute heavily to overall institutional drop-out rates between the first and second year. Although success rates vary by institutional type and by subject matter, Research I universities commonly cite a 15 percent drop-failure-withdrawal (DFW) rate in introductory courses. Comprehensive universities' DFW rates range from 22 percent to 45 percent in these courses. Community colleges frequently experience DFW rates of 40 percent to 50 percent or more.

Most of the weaknesses attributed to large introductory courses are generic in nature and have as their source the limitations of the predominant form of instruction in U.S. colleges and universities: the didactic lecture. An overwhelming body of research shows that students do not learn effectively from lectures, and testimony from the field corroborates the literature.

What's wrong with the lecture? The lecture method treats all students as if they were the same, as if they bring to the course the same academic preparation, the same learning style, the same motivation to learn, the same interest in the subject, and the same ability to learn. The reality is that students with weak skills need more individual attention and more opportunity for interaction, particularly at the beginning of the term. At the same time, students with strong skills are locked into a fixed time frame for completing the course. The large, impersonal lecture format simply cannot accommodate the broad range of differences among students.

Most lecture courses are notoriously ineffective in engaging students. The lecture format neither encourages active participation nor offers students an opportunity to learn collaboratively from one another. It does not provide adequate tutoring assistance, and consequently, students receive little individual attention. Even though individual help may be available during office hours, only a small fraction of students take advantage of this help. Most students simply study the text, turn in their homework, and take quizzes and exams.

The primary alternative structure for large-enrollment courses, the multiple-section model, suffers from 
problems of its own. In theory it allows greater interaction with students, but in practice, sections are often quite large and are dominated by the same presentation techniques as used in larger courses. In addition, the multiple-section model suffers from a lack of coordination. As a result, course outcomes vary considerably and, more important, are not always consistent with students' abilities. Clearly, making significant improvements in first-year courses can have a major impact on student success and retention.

\section{THE PROGRAM IN COURSE REDESIGN}

Supported by an $\$ 8.8$ million grant from the Pew Charitable Trusts, the Program in Course Redesign [1] was created in April 1999 to demonstrate how information technology could be used to address the significant academic problems experienced by first-year students at most institutions. The program is managed by the Center for Academic Transformation [2] at Rensselaer Polytechnic Institute. Selected from hundreds of applicants in a national competition, 30 institutions each received a grant of $\$ 200,000$, awarded in three rounds of 10 per year. Participating institutions include research universities, comprehensive universities, independent colleges, and community colleges in all regions of the United States.

Comparative research studies have shown that, instead of improving quality, most technology-based courses produce learning outcomes that are only "as good as" their traditional counterparts - the "no significant difference" phenomenon [3]. By and large, colleges and universities have not yet begun to realize the promise of technology to improve the quality of student learning, increase retention, and reduce the costs of instruction. In contrast, the goal of the Program in Course Redesign is to support colleges and universities in their efforts to redesign instruction using technology to achieve quality enhancements as well as cost savings.

All 30 redesign projects focus on large-enrollment introductory courses that have the potential to affect significant student numbers and generate substantial cost savings. Why focus on such courses? Because undergraduate enrollments in the United States are concentrated heavily in only a few academic areas. In fact, just 25 courses generate about half of all student enrollments in community colleges and about a third of enrollments in four-year institutions. The topics of these courses are no surprise and include introductory studies in disciplines such as English, mathematics, psychology, sociology, economics, accounting, biology, and chemistry. Successful completion of these courses is critical for student progress toward a degree.

Each of the 30 participating institutions is conducting a rigorous evaluation focused on student learning, comparing the outcomes of redesigned courses with those of courses with the same content delivered in a traditional (pre-redesign) format. Twenty-two of the 30 projects involved in the program have shown statistically significant increases in student learning; the other eight have shown equivalent learning to traditional formats. Of the 24 projects that measured retention, 22 have reported a noticeable decrease in DFW rates, ranging from 10 to 20 percent.

Each institution has developed a detailed cost analysis of both the traditional and the redesigned course formats, using a spreadsheet-based course-planning tool [4] developed by the center. Preliminary results show that all 30 institutions reduced costs by about 40 percent on average, with a range of 20 percent to 77 percent. Other positive outcomes associated with redesigned courses include better student attitudes toward the subject matter and increased student satisfaction with the new mode of instruction.

The Program in Course Redesign has produced many different models of how to restructure such courses to improve learning as well as to effect cost savings. To counter the belief that only courses in a restricted 
subset of disciplines — science or math, for instance — can be effectively redesigned, the program contains successful examples in many disciplines including the humanities (6), math and statistics (13), the social sciences (6), and the natural sciences (5). What do these projects have in common? To one degree or another, all 30 projects share the following six characteristics:

1. Whole course redesign. In each case, the whole course, rather than a single class or section, is the target of redesign. Faculty begin the design process by analyzing the amount of time that each person involved in the course spends on each kind of activity, a process that often reveals duplication of effort among faculty members. By sharing responsibility for both course development and course delivery, faculty save substantial amounts of time while achieving greater course consistency.

2. Active learning. All of the redesign projects make the teaching-learning enterprise significantly more active and learner-centered. Lectures are replaced with a variety of learning resources that move students from a passive note-taking role to an active learning orientation. As one math professor put it, "Students learn math by doing math, not by listening to someone talk about doing math.”

3. Computer-based learning resources. Instructional software and other web-based learning resources assume an important role in engaging students with course content. Resources include tutorials, exercises, and low-stakes quizzes that provide frequent practice, feedback, and reinforcement of course concepts.

4. Mastery learning. The redesign projects add greater flexibility for when students can engage with a course, but the redesigned courses are not self-paced. Rather than depending on class meetings, student pacing and progress are organized by the need to master specific learning objectives, which are frequently in modular format, according to scheduled milestones for completion.

5. On-demand help. An expanded support system enables students to receive assistance from a variety of different people. Helping students feel that they are a part of a learning community is critical to persistence, learning, and satisfaction. Many projects replace lecture time with individual and small group activities that take place either in computer labs-staffed by faculty, graduate teaching assistants (GTAs), or peer tutors - or online, enabling students to have more one-on-one assistance.

6. Alternative staffing. By constructing support systems consisting of various kinds of instructional personnel, the projects apply the right level of human intervention to particular student problems. Not all tasks associated with a course require highly trained, expert faculty. By replacing expensive labor (faculty and graduate students) with relatively inexpensive labor (undergraduate peer mentors and course assistants) where appropriate, the projects increase the person-hours devoted to the course and free faculty to concentrate on academic rather than logistical tasks.

Although all 30 projects have these characteristics in common, each has chosen a design model that implements the characteristics in a way that varies according to the discipline involved, the particular student audience, and the preferences of faculty. While the Program in Course Redesign is directed at a broad first-year student population at all types of institutions, we know that the redesign techniques have been particularly effective with minority students, community college students, and adult learners. For example,

- With an undergraduate minority student population of 46.4 percent, the University of New Mexico reduced its drop-failure-withdrawal rate from 42 percent to 18 percent in Introductory 
Psychology. At the University of Idaho, success rates in Intermediate Algebra for Hispanic students who are part of the College Assistance Migrant Program (CAMP) increased from 70 percent to 80 percent, and CAMP students surpassed the success rate for the entire algebra population as a whole.

- Two community colleges, Rio Salado College and Tallahassee College, respectively increased course completion rates from 59 percent to 65 percent in pre-calculus mathematics and from 56 percent to 62 percent in English composition.

- Two urban universities that serve a high percentage of adult learners, Florida Gulf Coast University and Indiana University-Purdue University Indianapolis, respectively reduced their DFW rates from 45 percent to 11 percent in a fine arts course and from 39 to 25 percent in Introductory Sociology.

To illustrate the impact of redesign on these at-risk and nontraditional students, brief case studies of redesign projects conducted by these institutions are presented here.

\section{A. The University of New Mexico}

Located in the heart of Albuquerque, the University of New Mexico (UNM) is one of only three Hispanic-Serving Carnegie Doctoral/Research-Extensive universities in the nation. With an undergraduate minority student population of approximately 46.4 percent (31.3 percent Hispanic, 5.5 percent Native American, and 9.6 percent other), UNM leads the nation's research universities in student diversity. UNM students are primarily commuters who also work 30 or more hours per week.

UNM redesigned General Psychology, its largest and most popular undergraduate "killer" course, which enrolls 2,250 students annually [5]. UNM's primary redesign goal was to improve the course's extraordinarily high 42 percent DWF rate, 30 percent of which were failures and a disproportionate number of which were minority students. UNM has one of the lowest student retention rates among public research universities. High failure rates in core curriculum courses such as General Psychology are known to have a strong negative impact on UNM's low overall retention and graduation rates.

The course redesign reduced the number of lectures each week from three to two and incorporated a weekly 50-minute studio session led by undergraduate teaching assistants, strong students from previous sections of General Psychology, or upper-division honors students. In-class activities were supplemented by interactive web- or CD-ROM-based activities and quizzes, offered on a 24/7 schedule. Students were able to interact online with other students and review concepts based on individual need. Online components used commercially available software that contained interactive activities, simulations, and movies. Students took repeatable quizzes each week requiring a C-level mastery.

The asynchronous learning environment also included programmed self-instruction (PSI), a learning technique that provides the individual student a self-paced method of learning new information. Using a branching sequence of interconnected questions, PSI includes repetition, examples, illustrations, and anecdotes to convey important psychology concepts. An active intervention strategy ensured that students were making progress. Graduate teaching assistants monitored quiz performance, counseling students with weak performance as to how to improve.

UNM's goal of reducing drop and failure rates in General Psychology has been achieved. The failure rate was reduced from previous levels of 30 percent to 12 percent, and the DWF rate fell from 42 percent to 18 percent. The number of students who received a $\mathrm{C}$ or higher rose from 60 percent to 76.5 percent, and there were more A and B grades than recorded in previous semesters. At the same time, the course was 
arguably more difficult, requiring students to cover completely a high-level introductory text.

\section{B. The University of Idaho}

Created in 1889, the University of Idaho (UI) is a comprehensive land-grant institution with principal responsibility in Idaho for performing research and granting the Doctor of Philosophy degree. UI offers 154 undergraduate majors, 71 master's programs and 25 doctoral degrees, and is home to the state's only law school.

UI redesigned three courses-Intermediate Algebra, Algebra, and Pre-Calculus - based on the Math Emporium model first developed at Virginia Tech [6]. The courses enroll a total of 2,428 students and were traditionally taught in a lecture format with assistance from a Mathematics Assistance Center. The traditional courses suffered from high DFW and repeat rates.

The prime objective was to move students from a passive learning environment to an active one in which the student controls and individualizes learning. Class meetings were eliminated; learning activities were moved to a learning center containing 72 computers in pods of four. Pods were designed for up to three students to work together at each monitor. Faculty, teaching assistants, and peer tutors worked with students individually and in groups. The courses used commercially-available math tutorial software that generated problems and offered immediate feedback. Short topical lectures were available on streaming video or video-on-demand. Since most of the course material was web accessible, students were not required to be in the center.

Students met weekly in focus groups of 40 to 50 students each to coordinate activities and discuss experiences and expectations. Aside from the weekly focus group meeting, students had the freedom to manage their learning time, types of learning activities, and rate of progress. Online bulletin boards and email provided a continuous means of communication between students and instructors.

Overall student performance as measured by grades based on comparable examinations and assignments has improved. In Algebra and Intermediate Algebra, the percentage of As and Bs was higher and the percentage of Cs, Ds and Fs was lower. In Pre-Calculus, the percentage of A and B grades also tended to be higher for redesign students, though the proportion of failures was not reduced dramatically. The redesign has been particularly successful with Hispanic students who are part of the College Assistance Migrant Program (CAMP). During the fall 2002 semester, however, these students achieved an 80 percent pass rate in Intermediate Algebra, compared with the previous 70 percent pass rate. CAMP students also surpassed the success rate for the entire algebra population as a whole.

\section{Rio Salado College}

Rio Salado College, one of 10 community colleges in the Maricopa County Community College District in Phoenix, places high value on creating convenient, high-quality learning opportunities for diverse population and specializes in customized programs and partnerships, accelerated formats, and distance delivery. Rio has been offering distance education for the last 20 years, with a focus on serving adult learners who work or have family commitments.

Rio redesigned four pre-calculus mathematics courses [7]. Before the redesign, the college had used mathematics software developed by Academic Systems to deliver its pre-algebra and college algebra courses via the internet. Although the internet classes showed a modest retention increase of about 2 percent over the print and mixed-media format of distance delivery, the overall retention rate was only 59 
percent. Rio wanted to increase retention and to maintain or increase the number of students who completed the course with a grade of $\mathrm{C}$ or better.

Because the Academic Systems software presented course content so well, instructors did not need to spend time delivering content. Prior to the redesign, the majority of instructors' time was spent troubleshooting technology problems, helping students navigate through the material, and advising students rather than helping them learn mathematics. The redesign added a nonacademic course assistant to address non-math-related questions (which constituted 90 percent of all interactions with students!) and to monitor students' progress, thus freeing the instructor to concentrate on academic rather than logistical interactions with students. As a result, one instructor was able to teach 100 students concurrently enrolled in any of four math courses.

Rio took advantage of the Academic Systems software's large bank of problems and answers for each topic to increase the amount and frequency of feedback to students. All assignments were graded on the spot by the software. Students knew what they had not mastered and were able to take appropriate corrective actions. Students could take end-of-module quizzes as soon as they were ready, moving quickly or slowly through the material. The software also provided a built-in tracking system that allowed the instructor and the course assistant to know every student's status (both time on task and progress through the modules) in each of the four courses.

By using these techniques, Rio was able to increase completion rates from 59 percent to 65 percent, while tripling the number of students handled by one instructor. Using the Academic Systems software ensured that all students who completed the course successfully had the same kinds of learning experiences. This means that they were more consistently prepared when they moved to the next course in the sequence or to other courses requiring a mathematical background.

\section{Tallahassee Community College}

Since 1966, Tallahassee Community College (TCC) has worked to expand educational opportunities to learners through a variety of instructional delivery mechanisms and formats, specifically, web-based college-credit courses. TCC ranks first among Florida community colleges in the enrollment of AfricanAmerican students, and first in the percentage who are A.A. degree completers. TCC's number of minority graduates ranks 53rd in the nation.

TCC redesigned College Composition, a required course serving approximately 3,000 students annually. The traditional format, which combined lecture and writing activities in sections of 30 students each, made it difficult to address individual needs. Considerable class time was spent reviewing and re-teaching basic skills, thus reducing the amount of time students had to engage in the writing process. Success rates were poor (less than 60 percent annually). Many students had to repeat the course, which placed a financial burden on the English Department and led to a heavy dependence on adjunct instructors. The redesign had two major components. The first involved using appropriate technologies to provide diagnostic assessments resulting in individualized learning plans; interactive tutorials in grammar, mechanics, reading comprehension, and basic research skills; online tutorials for feedback on written assignments; follow-up assessments; and discussion boards to facilitate the development of learning communities. Students submitted mid-stage drafts to online tutors at TCC or to SMARTHINKING, reducing the amount of time faculty spent grading papers. These activities took place outside the classroom and were accessible to students at any time.

The second component involved restructuring the classroom to include a wide range of learner-centered 
writing activities that fostered collaboration, proficiency, and higher levels of thinking. By shifting many basic instructional activities to technology, faculty could focus the classroom portion of the course on the writing process. Students worked in small groups or on individual writing efforts, depending on their identified needs.

During the 2002-2003 academic year, students in the fully redesigned sections had a 68.4 percent success rate, compared with 60.7 percent for the traditional sections. The overall success rate for all composition students was 62 percent for the 2002-2003 year, compared with 56 percent for the 1999-2000 year, representing a 13.6 percent decrease in the DWF rate. Faculty have observed that redesign students are more actively engaged in the learning process, are taking greater responsibility for their learning, are more independent and self-sufficient as learners, and are more adept at collaborative processes.

\section{E. Florida Gulf Coast University}

Opened in 1997, Florida Gulf Coast University (FGCU) was established to serve the needs of the southwest Florida region, one of the fastest growing areas in the United States. Located in Fort Myers, FGCU has experienced phenomenal growth for the past three years. FGCU is committed to increasing access to quality academic programs that emphasize student learning while controlling costs through creative teaching and course-delivery practices.

FGCU redesigned Understanding the Visual and Performing Arts, a required course in its general education program, to accommodate enrollment growth and achieve greater coherence and consistency [8]. FGCU's goal was to increase the number of As and Bs and to decrease the number of Ds and Fs. All students were moved into a single, fully online section, using a common syllabus, textbook, set of assignments, and course, website. Students were placed into cohort groups of 60 and, within these groups, Peer Learning Teams of six students each. The redesign allowed FGCU to maintain the most important elements of humanities courses-active engagement with ideas and a collaborative and experiential learning experience-while eliminating seat time completely.

The course included three modules, each of which had the same format, including an exam with both short-answer questions and a short-essay question. After reading chapters in the text, students repeatedly took low-stakes quizzes that provided feedback in preparation for the objective portion of the module exam. To prepare for the essay portion, students participated in web board discussions with their Peer Learning Teams, analyzing sample essays. These discussions increased interaction among students and developed critical thinking skills. Students also attended two arts activities in the community to gather material for two longer critical-analysis essays.

In the area of content knowledge, students demonstrated a markedly enhanced level of learning in the redesigned course. The average score on standardized exams in the traditional course was 72 percent and 85 percent in the redesigned course. The percentage of As and Bs on standardized exams went from 37 percent to 77 percent, and the percentage of Ds and Fs went from 37 percent to 10 percent.

\section{F. Indiana University-Purdue University Indianapolis}

Indiana University Purdue University at Indianapolis (IUPUI) is an urban research university created in 1969 as a partnership by and between Indiana and Purdue Universities. Because it grants degrees in 185 programs from both universities, IUPUI offers the broadest range of academic programs of any campus in Indiana. IUPUI ranks among the top 15 in the country in the number of first professional degrees it confers and among the top 5 in the number of health-related degrees. 
IUPUI redesigned Introduction to Sociology, which enrolls approximately 2,000 students annually, to encourage greater collaboration among students, increase student learning, and improve student success rates [9]. In the traditional course, 39 percent of students received a D or F or withdrew from the course. The traditional lecture-and-testing format did not offer students the opportunity to learn collaboratively from one another. The course redesign involved eliminating the multiple-section course format and substituting a common format that included online learning modules, threaded discussions, interactive computer-based testing and an interactive research module.

Collaborative learning theory suggests that the more often students are able to engage in extended discussion about the course material, the more likely they are to learn it. The redesign introduced collaborative computer work in a research module common to all sections, with a special focus on the collection and analysis of data. The software also created a common discussion space that allowed all students (resident and commuter, traditional and nontraditional) to work collaboratively without location and time restrictions.

A traditional problem with classroom-based groups on IUPUI's urban campus is that students have trouble meeting with each other. Increasing the ease and amount of communication is especially important in large sections where instructor-student and student-student interaction is often inhibited by class size. Interactive testing allowed students to take exams outside of class, which freed in-class time for additional student-faculty interaction. A course management system allowed faculty to monitor students' progress and participation, permitting early intervention in problem situations.

In the fall 2000 pilot, the percentage of students receiving a D or F or withdrawing dropped from 39 percent to 33 percent; in spring 2001, it was 30 percent; in fall 2001, it dropped to 25 percent. In fall 2000, students in redesigned sections had higher (.10 level) grades. In spring 2001, redesign students had significantly higher (.05 level) grades than those in the traditional format. Finally, in fall 2000, a difference-of-means test showed that students in redesigned sections scored significantly higher (.05 level) on a set of common questions measuring understanding of key sociological concepts.

\section{CONCLUSIONS}

In addition to experiencing the generic quality and cost problems faced by all colleges and universities, community colleges face problems particular to their student populations. They need to design more flexible schedules for working adult students, create a greater sense of community or engagement for commuting students, address the special needs of English-as-second-language students, and serve at-risk students more effectively. The Program in Course Redesign has shown how information technology and asynchronous learning strategies can be used to address these challenges when combined with proven pedagogies, and do so while reducing instructional costs. The six institutions described in this article reduced their course costs on average by 35 percent, with a range of 20 percent to 42 percent. Their successes are easily transferable to community colleges throughout the country. The result: greater learning for less cost and, most importantly, more students able to achieve their academic goals.

\section{REFERENCES}

1. http://www.center.rpi.edu/PewGrant.html

2. http://www.center.rpi.edu/

3. http://teleeducation.nb.ca/nosignificantdifference/

4. http://www.center.rpi.edu/PewGrant/Tool.html 
5. http://www.center.rpi.edu/PewGrant/RD3 Award/UNM.html

6. http://www.center.rpi.edu/PewGrant/RD2 Award/UI.html

7. http://www.center.rpi.edu/PewGrant/rd1award/rio.html

8. http://www.center.rpi.edu/PewGrant/RD3\%20Award/FGCU.html

9. http://www.center.rpi.edu/PewGrant/rd1award/iupui.html

\section{ABOUT THE AUTHOR}

Carol A. Twigg is Executive Director of the Center for Academic Transformation at Rensselaer Polytechnic Institute. The Center's mission is to serve as a source of expertise and support for those in higher education who wish to take advantage of the capabilities of information technology to transform their academic practices. 